\title{
Chinese Ju and World Football
}

\author{
Lin Yang* \\ Department of Physical Education, Nanjing Institute of Technology, Nanjing 211167, China
}

linyang_njit@126.com

KeyWords: Ju, Cultural Form, Genetics, Silk road, Soccer

\begin{abstract}
According to the cultural form theory, this article studies the fact that Chinese Ju has been evolved into the modern football, as well as the premises and evolution process of such fact, thereby demonstrating how the Chinese Ju has been evoved into the world football, and become a modern game. Specifically, the premises are the Chinese culture and historical records, and the evolution process is synchronous with the evolution of the Silk Road. Through the study, the following conclusions are drawn: 1 . The ancient Chinese Ju was evolved into the world footable today; 2. China is the origin of the modern soccer; and 3. An inflatable ball with liner was invented in the middle of the Tang Dynasty of China.
\end{abstract}

\section{Emergence of $\mathrm{Ju}$ - historical facts}

The earliest record about Ju was in the Four Classics of Huang Di at the beginning of the Warring States period, which describes that Ju appeared in the Huang Di Period more than 4600 years ago. Sima Qian's Historical Records has the most credible records about Ju, Later than that, the records about $\mathrm{Ju}$ in Liu Xiang's Bie Lu proved Ju was a game in the Huang Di Period. As recorded in Huan Kuan's YanTieLun, Ju was especially popular in the Western Han Dynasty. Yang Xiong's Fa Yan recorded the making craft of Ju was popular and has its unique style; and Xu Jian's ChuXueji recorded that an inflatable ball was invented in the Tang Dynasty. After the Western Han Dynasty, there are plenty of history records about Ju.

\subsection{As the first record about Ju appeared in the Four Classics of Huang Di between 475 and 300 $B C$, Ju had existed in the Huang Di Period.}

In AD 1973, the Four Classics of Huang $\mathrm{Di}^{[1]}$ between 475 and 300 BC was unearthed from Tomb No.3 of the Western Han Dynasty Hunan, at Mawangdui, Changsha City, China. According to textual research, the text in official script was copied with ink between about 205 to 195 BC, and it was initially created between about 475 and 300 BC. Where, an article with the title of Shi Da Jing.Zheng Luan records that there was a war between the Huang Di tribe and the Chi You tribe in the Zhuolu in the Huang Di Period (2697 2599 BC) ${ }^{[2]}$. The war was very tragic, and the Huang Di tribe captured and killed Chi You, greatly winning the war. For the release of hate, the tribe stripped Chi You's skin and made it into the arrow target, and the guys who hit exactly a lot would be rewarded. His hair was hung high enough, called as Chi You Flag. And then, they stuffed his stomach with his hair to make a ball called Ju. Ju was used for playing by people. Th guys who kicked it successfully would be rewarded. This is the earliest record about Ju in the historical books.

At that time, Ju was a ball made with Chi You's stomach stuffed with his hair. However, the ball was neither regular in shape nor beautiful. It was played just for excitement and release of hate, and could not bring happiness as a game. However, as the first stuffed ball recorded in the human history, it indicates a forward step compared to jade balls and stone balls. In Chinese ancient times, the round balls were mosted made of jade or stone, so the Chinese character for ball (球) has a component of “玉”. Till the Huang Di period, the ball was initially made with Chi You’s skin. And later than that, people gradually made a ball with leather blocks, so such ball was called Ju (鞠) . As you see in the Chinese character for Ju, there is a component of “革” (meaning leather). 


\subsection{The Historical Records between 96 and 91 BC records that Cuju was popular in the Spring and Autumn period.}

Si Maqian completed his works, i.e. the Historical Records ${ }^{[3]}$ between 96 and 91BC, in which it is recored that: When persuading King Xuan of Qi State in 328 BC, Su Qin described Linzi as "Linzi is very rich, and the strength is very strong, the public are all vigorous and happy, playing Yu and Se or performing Qin and Zhu (Yu, Se, Qin and Zhu are all musical instruments in that times), or participating in cock and dog fighting games, or playing Cuju”, which vividly depicts the strength and prosperity of Qi State, and the prevalence of Cuju.

\subsection{As recorded in the Yan Tie Lun between 81 and $70 \mathrm{BC}$, Cuju was especially popular in the 70BC of the Western Han Dynasty.}

Huan Kuang's Yan Tie Lun ${ }^{[4]}$ records that the wealthy people were living more luxuriously, and they do nothing but enjoying themselves to the utmost, such as going fishing, walking with dog, playing Cuju or participating in cock fighting. The Yan Tie Lun was a political anthology which was developed according to the Yan Tie Conference held in the 6th year (81BC) of Shiyuan in the Zhao Emperor of the Han Dynasty, and completed before the 4th year (70BC) of Xuan Emperor of the Han Dynasty.

\subsection{The records in Bie Lu between 26 and 8 BC proved that Ju had appeared in the Huang Di period.}

In 26 BC, Liu Xiang was ordered to collate the ancient books and records. He spent 19 years reviewing and collating the imperial book collections piled like a hill. Once a book is reviewed, he made a category and gave the brief description of the book, thus developing the book Bie $\mathrm{Lu}^{[5]}$. The Bie Lu records that "It is said Cuju was made by Huang Di."

\subsection{The Fa Yan in 8 BC records that the making craft of Ju was popular and has its unique style in the Western Han Dynasty.}

With the making method of Ju as an example, Yang Xiong discussed the importance of rules to a society in his works, i.e. Fa Yan ${ }^{[6]}$. He said: "Making chess pieces by sawing wood or cooking skin to make a Ju should follow certain rules. Similarly, a society should have its rules and laws as well. Obviously, there were specific specifications annd standards for making a Ju in the Han Dynasty. At that time, Ju was mostly maded by sewing cooked skin and stuffed with hair or other fillers. The Fa Yan emphasized the importance of rules and laws by taking Ju as an example, which reflects the progress and manufacture scale of $\mathrm{Ju}$ in the Han Dynasty on the one hand, and also indicates the prevalence and the great influence on the society of Cuju.

\subsection{The History of the Han Dynasty between AD 54 and 92 records that Cuju was particularly popular in the early period of the Eastern Han Dynasty.}

Ban Gu collected the 25 Articles about Cuju in the History of the Han Dynasty ${ }^{[7]}$, and Yan Shigu gave the notes following the articles: "Ju is a solid soft and light ball made with animal skin or offals, and stuffed with hair or other objects. Cuju is the game with Ju. The History of Art And Literature in the History of the Han Dynasty included the 25 Articles about Cuju in the books for military training. As Cuju became popular and is gradually evolved in to a folk game with a variety of playing rules, it was finally listed in the sports competitions as an item. Actually, the 25 Articles about Cuju in the History of the Han Dynasty is the earliest professional sports books of China, and the first professional sports books in the world.

In the dynasties later than that, there have been a lot of records about Ju and Cuju in the historical materials, including official histories, folk histories, poetry, song, opera, novels, biography and so on. 


\section{Rudiment of Ju - Stuffed Ju}

\subsection{Stuffs of Ju}

As recorded in an article with the title of Shi Da Jing•Zheng Luan in the the Four Classics of Huang Di, Ju was made with offal and stuffed with hair. The index of the Biography of General Wei in the Historical Records states that "Ju has an outer layer made of skin, and is stuffed with hair. Cuju is a game with Ju", which indicates that Ju was still a stuffed ball, but its making craft had been progressed. The outer layer was made of durable leather instead of animal offals. And Cuju became a ball game."

Ban Gu's Biography of Mei Cheng in the Historical Records in the early period of the Eastern Han Dynasty records that "Ju is made of skin". And Yan Shigu ${ }^{[8]}$ made a note in the 25 Articles about Cuju of the History of Art And Literature that "Ju is a solid soft and light ball made with animal skin or offal, and stuffed with hair or other objects. Cuju is the game with Ju.” Besides, he also described the making method and the usage of Ju. Shang Binghe ${ }^{[9]}$, a modern scholar says "Ju was stuffed with hair, light and elastic and easy to be bounded up. The outer layer of Ju was made by sewing leather blocks, very durable. One Ju might be used for several years. Besides, it had the appropriate weight, easy to control, without worry of gas leakage. When kicking it for playing, the flexibility is satisfying. Such a solid Ju had always been used till the Tand Dynasty. It can be said that Ju before the Tang Dynasty was solid.

\subsection{Wool-ball Ju}

In fact, there was not only Ju made with stuff, but also the solid Ju made with wool thread ball. Yin Zhao from the Eastern Han Dynasty said in his Fengsu Tongyi ${ }^{[10]}$ that "The wool thread ball is also used as Ju." Guo Pu from the Eastern Jin Dynasty said in his Sancang Jiegu ${ }^{[11]}$ also gave the description about Ju made of wool thread ball. The so-call wool thread ball is namely the Ju made by winding wool thread. Besides, people also made Ju by knitting a small ball-like bag, and stuffing it with feathers or hair. Such type of Ju was easy to make, but inferior to the one made of leather in terms of perfomance and durability.

\section{Prevalence of Ju - Inflatable Ball}

\subsection{The inflatable Ju was invented in the Tang Dynasty.}

The Tang Dynasty is a watershed in the evolution history of Ju. With the invention of the inflatable $\mathrm{Ju}$, the making craft of Ju experienced a revoluation, which led to a fundamental change, namely, a stuffed Ju became a hollow but inflatable Ju. The new-style Ju was made of animal bladder wrapped with cooked skin, reducing the weight and improving the controllability. This is the first invention in the history of the world. As recoreded in the History of the World Sports, England invented the blowing balloon in the 11th century, which was three or four hundred years later than the Tang Dynasty of China. Therefore, it was ancient Chinese who invented the inflatable ball.

As described by Xu Jian in his ChuXueji ${ }^{[12]}$, "The ancient people made Ju by rolling hair, but today,we make it with leather on the outer layer, and an animal's bladder inside by inflating. Thus, a Ju has leather outside and gas inside”. Zhong Wupo also mentioned the making method of Ju in his Balloon Fu, "Ju is made by sewing square leather blocks, and it is square at the beginning, but becomes round after inflated without leakage".

The Quan Tang Shi Hua ${ }^{[13]}$ records a fun thing about a poet named Pi Rixiu of the Tang Dynastry: Pi Rixiu laughed at Gui Rian's children with the surname of Gui (homophonic to turtle in Chinese) by creating a poem with the theme of turtle: "You have hard bone but old body which will finally look bad after you die. Even if you can retract your head under the shell, but you dare not extend it throughout your life.”Gui Rian was unsatisfied at such a poem, and also composed a poem with the theme of Ju for revenge : "You are made by cutting a skin into multiple pieces after roasted 
on fire and cooked in water. And then, you will be inflated with air and played with by kicking. This example is cited here just for presenting the description about Ju. According to the poem composed by Gui Rian, we know that Cuju was popular in the Tang Dynasty, its making craft had been very mature, and widely known, and the poet composed a poem with Ju as the theme, indicating it was very common in life on the one hand; and on the other hand, the making craft was complicated and complex. Cooking skin was the first step. The whole craft involved roasting on fire and cooking in warm water repeatedly until the oil was removed and the skin became flexible. Once the outer layer was prepared, an animal's bladder was also required. After processed, the bladder would be put inside the outer layer and inflated, so as to make the Ju look round.

\subsection{The Song Dynasty improved the making method of inflatable Ju and specified the weight of the same}

In the Song Dynasty, another innovation on the making method of Ju was achieved. In the Cuju $\mathrm{Pu}$ of the Southern Song Dynasty, the making method of Ju is described in details. The Ju in the Song Dynasty had three differences compared to that in the Tang Dynasty. Firstly, the outer layer was composed of up to 12 leather blocks. Obviously, the more the leather blocks are used, the rounder the Ju will be, but it does not mean the more the better; secondly, the sewing method was more ingenious. The leather blocks were sewed one by one, combined with turnover sewing, thus the sewing thread ends were not exposed outside, and the Ju looked rounder; and thirdly, the weight of Ju was fixed. It was specified as 14 liang, equal to about today's 560 grams, which is quite close to the football weight specified by the FIFA today.

\section{Change of Ju - Football}

Chinese Cuju game is an ancient sport. In the long history, it was spread to Europe through the ancient Rome along the Silk Road. Based on the fact that the modern exists, the article studies the process that $\mathrm{Ju}$ was evolved into football with the genetic method, according to the historical records about Ju and its spread along the Silk Road. It combines the history and logic in the order of historical events on the basis of the cultural form theory, discusses and explains the evolution process of Chinese $\mathrm{Ju}$, and represents the history of Ju, demonstrating that Chinese Ju became football in England, and then became the modern football, and Cuju was evolved into the football game popular in the world.

\subsection{Genetic Method}

The genetic method ${ }^{[14]}$ for the study of the history was initially a method in the field of natural science research, and then gradually applied to the field of humanitiy and social science research. The materialism and materialist dialectics make the method become more scientific, thus forming a genetic method with the universal meaning. On the basis of natural law philosophy, the genetic method focuses on speculation and evolution, starting from the hypothesis of human natural state and deducing the origin and vicissitude of human social history and it is a method to perform philosophical thinking on the history of human society. The genetic method can unify the history and logic in the chronological order of historical events, to form a scientific historical interpretation, and further discuss the reason for historical changes, thus representing the history finally. Therefore, the genetic method is a method used for the research on the fact and its premise and process of occurence, with scientific and practical features.

\subsection{Genetic Method and Change of Ju}

In the period of China's Western and Eastern Han Dynasties, the feudal society of China was getting prosperous gradually, while Europe was being in the ancient Roman Empire Times, belonging to the slavery society stage. Chinese culture affected many countries and regions in West Asia, and the ancient Roman culture also affected the European and Mediterranean regions. However, there was lack of mutual understanding, exchanges and absorption between the East and 
the West in that period. In that case, the ancient Silk Road of China leading to the ancient Roman Empire played an important role in the history of the world culture, and promoted the cultural exchanges in the process of material exchanges, acting as the main road for politic, economic, cultural exchanges between the East and the West.

The Silk Road refers to the ancient trade route starting from China, and connecting Asia, Africa and Europe. Narrowly speaking, the Silk Road refers to the land Silk Road, while broadly speaking, it includes both the land Silk Road and the sea Silk Road.

The land Silk Road was initially opened in the Qin and Han Dynasties, and it was a trade route connecting the hinterland of China and various regions of Europe, remained and used till the 16th century. In the Western Zhou Dynasty, China's silk was sold to the Western Regions via Hexi Corridor. When it was the Spring and Autumn Period, silk had become the most popular product in West Asia, and the sales range extended to the Mediterranean coast. The trips of imperial envoy Zhang Qian to the Western regions opened up a new era for the exchange between the ancient East and West. Thereafter, the small-scale, intermittent and private exchanges between the East and the West became the large-scale, sustained and official exchanges. The land Silk Road started from Changan in the Western Han Dynasty (Luoyang in the Eastern Han Dynasty) and extended to Dunhuang via the Hexi Corridor. From Dunhuang, it was divided into the southern route and the northern route: the south route extended from Dunhuang to Dayueshi and Anxi after running through Congling, and to Tiaozhi and Daqin (the ancient Roman Empire) westward via Loulan, Yutian and Shache; and the northern route extended from Dunhuang to Jiaohe, Guizi and Shule respectively, and to Dawan after running through Congling, and to Daqin westward via Anxi.

The sea Silk Road was also initially opened in the Qin and Han Dynasties, and it was the expanded connecting route for the ancient Chinese overseas trade. The famous Chinese ceramics, tea, silk and iron products were sold to other countries via this sea route, and the western spices were also imported to China via it as well. The sea Silk Road has three routes. The first one was the Orient route, from China's coastal ports to North Korea and Japan; the second one was the southeast Asia route, from China's coastal ports to Southeast Asian countries; and the third one was the Western world route, from China's coastal ports to South Asia, East African coastal countries, and to Europe via Arab.

The land and sea Silk Roads extended to the European countries via Central Asia, West Asia and the Roman Empire. Through the Silk Roads, China's goods, technology and culture were gradually spread to the West. At the same time, the Western goods, literature, art, religion and musical instruments were also introduced into China. In particular, the ancient nomadic or tribal people, businessmen, believers, soldiers and investigators carried out trading activities and cultural transmission along the land and sea Silk Roads. Naturally, China's $\mathrm{Cu}$ game was also spread to the East and the West along the land and sea Silk Roads. With the increase of merchandise trade activities as well as the integration and infiltration of Eastern and Western cultures, the Cuju game popular in the Tang Dynasty was also introduced to Europe, and spread to England where, it was was gradually evolved into the football game in the Middle Ages, and then into the modern football game popular in the world today, thus Chinese Ju being evolved into the world football.

After spread to Japan along the sea Silk Road, Cuju of China's Tang Dynasty was combined with the Japanese local culture quickly, and became popular across the Japan Court, and then was gradually evolved into Japanese-style Cuju. Japanese $\mathrm{Ju}$ is nearly oval, with a diameter of 18 to $20 \mathrm{~cm}$, a weight of 100 to150 grams, and a small elasticity. It is mostly made of deer skin, and the joint part between two pieces of dear skin is made of horse skin. Inside Japanese Ju, a small amount of barley grains are filled. Even today, there are still Cuju performances all over Japan when a New Year comes.

\section{Cultural Form and Evolution of Ju}

According to Marx's theory of the three major cultural forms ${ }^{[15]}$, the human's era of civilization experiences three cultural forms, i.e. agricultural culture, industrial culture and post-industrial 
culture in sequence. The three cultures are successive, and the cultural level is continuously improved. Culture is the performance of human nature, so the flow of culture is also dictated by human nature. As a producct of concept forms, culture is always in the process of continuous producing and abanonment. Only those that have important value and vitality can be accumulated, saved and inherited, becoming a main component of the later culture. From the cultural genetics point of view, the culture created by the ancient Chinese Cuju game will be inherited, accumulated, generated and evolved, and it will inevitably be replaced by a more advanced culture, and form a sports culture. Therefore, Cuju became football game. Thus it is a historical necessity that Chinese Ju became the modern football. The ancient Chinese Ju was evolved into the modern football under the background of the west culture, and simultaneously, the ancient Chinese Cuju game was evolved into the modern football game in Europe. Obviously, China is the origin of the modern football. The advanced sports culture formed by the modern football has been spread throughout the world, and become an important part of the world's sports culture.

\section{References}

[1] Four Classics of Huang, collated and annotated by Xiong Chunjin, Beijing: China Yanshi Press, 2012.

[2] Chinese Dynastic History Chart, compiled by the History Researcg Group of Chinese Academy of Social Sciences Institute, Beijing, Zhonghua Book Company, 2014.

[3] Sima Qian, Historical Records, Beijing, Zhonghua Book Company, 2004.

[4] Yan Tie Lun, collated and annotated by Wang Liqi, Beijing, Zhonghua Book Company, 1992.

[5] Liu Xiang, Bie Lu, Shanghai, Shanghai Chinese Classics Publishing House, 2008.

[6] Yang Xiong, Fa Yan, Jinan, Shandong Friendship Publishing House, 2001.

[7] Ban Gu, History of the Han Dynasty, Beijing, Zhonghua Book Company, 1962.

[8] Ban Gu, History of the Han Dynasty, annotated by Yan Shigu, Shanghai: Commercial Press, 1958.

[9] Shang Binghe, Investigation on Ancient Social Customs of all Dynastsies, Shanghai, Shanghai Bookstore, 1991.

[10] Ying Shao, A Compendium of Popular Customs, Tianjin, Tianjin Ancient Books Publishing House, 1988.

[11]Li Fang et al, Tai Ping Yu Lan, photocopied by Zhonghua Book Company, 1966.

[12] Xu Jian, ChuXueji, Beijing, Zhonghua Book Company, 1962.

[13] You Mao, Quan Tang Shi Hua, Beijing, Zhonghua Book Company, 1985.

[14]Zhang Naihe, Genesis Methodology and Historical Studies, Collected Papers of History Studies, 2007 (5), 43-50.

[15] Marx and Engels, Karl Marx and Frederick Engels, People's Publishing House, 1980. 